\title{
The Influence of Antihypertensive Agents on Gircadian Rhythms of Blood Pressure and Heart Rate in Patients with Essential Hypertension
}

\author{
Masanori Munakata, Yutaka Imai, Junichiro \\ Hashimoto*, Hiromichi Sakuma, Hiroshi Sekino $\dagger$, \\ KeIShi ABe* and KaOru Yoshinaga \\ The Second Department of Internal Medicine and \\ *Department of Clinical Biology and Hormonal \\ Regulation, Tohoku University School of Medicine, and \\ $\dagger$ Kojinkai Central Hospital, Sendai 980
}

Munakata, M., Imai, Y., Hashimoto, J., Sakuma, H., Sekino, H., Abe, K. and Yoshinaga, K. The Influence of Antihypertensive Agents on Circadian Rhythms of Blood Pressure and Heart Rate in Patients with Essential Hypertension. Tohoku J. Exp. Med., 1992, 166 (2), 217-227 — The effects of once-daily administration of calcium (Ca) channel blockers, $\beta$-blockers and angiotensinconverting enzyme (ACE) inhibitors on circadian rhythms of blood pressure (BP) and heart rate (HR) were studied using the cosinor method. Sixty-two recruited patients with essential hypertension (WHO stage I or II) were divided into three groups based on the class of administered drugs. In the Ca channel blocker group ( $n=37$, age $54 \pm 9.0$ years), 18 patients were given YM 730 at a mean dose of $11 \pm$ $4.0 \mathrm{mg} /$ day (mean \pm s.D.), 8 were given nitrendipine $(11 \pm 6.7 \mathrm{mg} /$ day $)$, and 11 were given nisoldipine $(8 \pm 6.4 \mathrm{mg}$ /day). In the $\beta$-blocker group $(n=15$, age $42 \pm 13.5$ years), 13 patients were given atenolol $(44 \pm 11.0 \mathrm{mg} /$ day), 1 was given nadolol ( 30 $\mathrm{mg}$ /day), and $\mathrm{l}$ was given sustained-release propranolol (60 mg/day). In the ACE inhibitor group ( $n=10$, age $56 \pm 8.7$ years), 7 patients were given enalapril $(6 \pm 2.8$ $\mathrm{mg}$ /day), and 3 were given lisinopril ( $20 \mathrm{mg}$ /day). Ambulatory BP monitoring (ABPM) was performed before and during treatment. Mean arterial pressure (MAP) and HR were monitored under ambulatory conditions every five minutes for $24 \mathrm{hr}$ with a finger volume oscillometric device. In all three groups, the mesor of MAP decreased significantly, while the amplitude and acrophase did not change during treatment. $\beta$-Blockers reduced the amplitude as well as the mesor of $\mathrm{HR}$. Ca channel blockers increased the amplitude of $\mathrm{HR}$ without influencing the mesor. ACE inhibitors had no effect on the circadian rhythm parameters of HR. These results suggest that $\mathrm{Ca}$ channel blockers, $\beta$-blockers and ACE inhibitors lowered $\mathrm{BP}$ throughout the day without changing the circadian BP rhythm. However, the three drug classes may have different influences on the autonomic nervous system that regulates circadian cardiac rhythm.— circadian rhythm; blood pressure; heart rate; antihypertensive agents; essential hypertension 
It is well known that blood pressure (BP) and heart rate (HR) reveal circadian rhythm (Millar-Craig et al. 1978a). Although the precise mechanisms mediating such rhythms have not been elucidated, involvement of both internal factors-such as humoral or neural systems (Delea 1979) - and external factors - such as physical and mental activities (Floras et al. 1978) - is suspected.

Antihypertensive drugs may affect circadian BP rhythm through an alteration of internal mechanisms related to BP regulation. Many investigators have reported the results on clinical trials that assessed the effects of antihypertensive drugs on circadian BP rhythm. These results seem to be qualitative rather than quantitative, however, since the pattern of circadian BP rhythm has been extrapolated from the time-trend graph of averaged BP plotted over $24 \mathrm{hr}$ periods. Thus the individual response of circadian BP rhythm to drug treatment has never been clarified.

To quantitatively assess circadian BP rhythm, the cosinor method is useful (Halberg et al. 1972). This method characterizes the circadian rhythm using three parameters and evaluates the circadian rhythm on both a population and individual basis. In this study, we examined the effects of three classes of antihypertensive agents on the circadian BP rhythm of patients with essential hypertension using the cosinor method. We also focused on the circadian HR rhythm to assess the effects of these drugs on the circadian rhythm of autonomic control of the heart.

\section{Methods}

Subjects

Patients with essential hypertension were referred to us from clinics outside the Kojinkai Central Hospital. Hypertension was diagnosed if seated casual BP obtained on three separate occasions during the follow-up period was $140 / 90 \mathrm{mmHg}$ or higher in those

TABLE 1. Patient characteristics in each drug group ${ }^{\mathrm{a}}$

\begin{tabular}{|c|c|c|c|c|c|c|}
\hline $\begin{array}{l}\text { Patient } \\
\text { group }\end{array}$ & $n$ & Age & $\begin{array}{c}\text { Male/ } \\
\text { Female }\end{array}$ & \multicolumn{3}{|c|}{ Drug and dose (mg/day) } \\
\hline $\mathrm{Ca}^{\mathrm{b}}$ & 37 & $54 \pm 9.0$ & $10 / 9$ & $\begin{array}{c}\text { YM 730 } \\
(n=18) \\
11.1 \pm 4.0\end{array}$ & $\begin{array}{c}\text { Nisoldipine } \\
(n=11) \\
7.9 \pm 6.4\end{array}$ & $\begin{array}{c}\text { Nitrendipine } \\
(n=8) \\
10.7 \pm 6.7\end{array}$ \\
\hline$\beta$ & 15 & $42 \pm 13.5$ & $3 / 12$ & $\begin{array}{c}\text { Atenolol } \\
(n=13) \\
44.2 \pm 11.0\end{array}$ & $\begin{array}{c}\text { Nadolol } \\
(n=1) \\
30\end{array}$ & $\begin{array}{c}\text { Propranolol LA } \\
(n=1) \\
60\end{array}$ \\
\hline $\mathrm{ACEI}$ & 10 & $56 \pm 8.7$ & $5 / 5$ & $\begin{array}{c}\text { Enalapril } \\
(n=7) \\
6.1 \pm 2.8\end{array}$ & $\begin{array}{c}\text { Lisinopril } \\
(n=3) \\
20\end{array}$ & \\
\hline
\end{tabular}

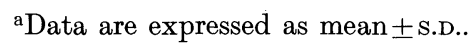

${ }^{\mathrm{b}} \mathrm{Ca}$, calcium channel blocker; $\beta, \beta$-blocker; ACEI, angiotension-converting enzyme inhibitor. 
under 40 years of age and $160 / 95 \mathrm{mmHg}$ or higher in those 40 years of age or more. The patients were given either placebo or no treatment for at least a 2-week follow-up period, during which the first ambulatory BP monitoring (ABPM) was performed. Overall, 62 untreated patients with essential hypertension at WHO stage I or II were recruited. The patients were divided into three groups and given a long-acting dihydropyridine-derived $\mathrm{Ca}$ channel blocker, a $\beta$-blocker or an angiotensin-converting enzyme (ACE) inhibitor once daily after breakfast. A second ABPM was performed when either a sufficient hypotensive effect was observed or the dosage of the drug reached the maximum level. The duration of treatment ranged from 4 to 8 weeks. Table 1 lists the patient characteristics of each treatment group.

\section{Blood pressure monitoring}

The device used in the present study (UBP-100, UEDA, Tokyo) automatically monitored systolic BP (SBP), mean arteriol pressure (MAP) and HR of the finger, using the volume-oscillometric method. Diastolic BP (DBP) was calculated according to the conventional formula : $\mathrm{DBP}=(3 \times \mathrm{MAP}) / 2$. The theoretical basis of this method and the technical details of this instrument have been described elsewhere (Yamakoshi et al. 1982a, b). The method was designed to measure BP by detecting local arterial pulsation using a photoelectric plethysmograph that was placed just below the occluding cuff. During the gradual increase or decrease in cuff pressure, the photoplethysmographic pulsations showed characteristic changes in amplitude; the systolic end-point and maximum amplitude were in good agreement with SBP and MAP in the studied arterial segment. The use and clinical application of this device has been reported elsewhere (Imai et al. 1987). In this study, BP and HR were measured every five minutes for $24 \mathrm{hr}$. All BP monitoring was performed on outpatients. Since external factors-such as physical activity, sleep and wakefulness - have considerable influence on the circadian BP rhythm, patients were asked to obey the following instructions : (1) avoid hard exercise, and (2) standardize the time of meals and hours of sleep as much as possible. Patients who complained of insomnia were excluded from the study.

\section{Cosinor analysis}

In this study, BP was represented by MAP. First, we calculated hourly mean values of MAP and HR from the data recorded every five minutes with the UBP-100 system. Then a cosine curve with a period of $24 \mathrm{hr}$ was fitted to the hourly mean data using the method of least squares. The following parameters were estimated from the best fitting curve; the mesor (rhythm adjusted mean), the amplitude (half of the total extent of predictable change) and the acrophase (lag of crest time in the best fitting cosine function in relation to a given reference time [i.e. zero time]). F statistics was used to test the zero-amplitude hypothesis for a significant circadian rhythm. A basic program for determining cosinor parameters and a significant rhythm were developed (Munakata et al. 1991) based on previous reports (Halberg et al. 1972 ; Nelson et al. 1979).

\section{Statistical analysis}

A significant circadian rhythm was not necessarily detected in every subject. The frequency of occurrence of a patient with a significant circadian rhythm (i.e., the rhythm detection rate) was compared before and during treatment using the chi square test $(p<$ 0.05). The data of the cosinor parameters were expressed by mean \pm s.D.. The paired Student's $t$-test was used for the comparison of each parameter before and during treatment.

\section{RESULtS}

The rhythm detection rates of MAP and $\mathrm{HR}$ tended to increase during 
TABLE 2. Rhythm detection rates for mean arterial pressure (MAP) and heart rate (HR) before and during treatment

\begin{tabular}{|c|c|c|c|c|c|c|c|}
\hline & & \multicolumn{3}{|c|}{ MAP } & \multicolumn{3}{|c|}{$\mathrm{HR}$} \\
\hline & & $\begin{array}{c}\text { rhythm } \\
(+)\end{array}$ & $\begin{array}{c}\text { rhythm } \\
(-)\end{array}$ & $\begin{array}{l}\text { rhythm detection } \\
\text { rate }\end{array}$ & $\begin{array}{c}\text { rhythm } \\
(+)\end{array}$ & $\begin{array}{c}\text { rhythm } \\
(-)\end{array}$ & $\begin{array}{l}\text { rhythm detection } \\
\text { rate }\end{array}$ \\
\hline \multirow[t]{2}{*}{$\mathrm{Ca}^{\mathrm{a}}$} & Before & 23 & 14 & 62 & 34 & 3 & 92 \\
\hline & During & 28 & 9 & 76 & 34 & 3 & 92 \\
\hline \multirow[t]{2}{*}{$\beta$} & Before & 9 & 6 & 60 & 9 & 6 & 60 \\
\hline & During & 12 & 3 & 80 & 12 & 3 & 80 \\
\hline \multirow[t]{2}{*}{ ACEI } & Before & 8 & 2 & 80 & 10 & 0 & 100 \\
\hline & During & 8 & 2 & 80 & 10 & 0 & 100 \\
\hline
\end{tabular}

${ }^{\mathrm{a}} \mathrm{Ca}$, calcium channel blocker; $\beta, \beta$-blocker; ACEI, angiotensin-converting enzyme inhibitor.

$\beta$-blocker treatment (Table 2). An increase in the rhythm detection rate of MAP was also observed during $\mathrm{Ca}$ channel blocker treatment. However, none of these changes were statistically significant. ACE inhibitors did not affect the rhythm detection rate of either MAP or HR.

In all three groups, the mesor of MAP decreased during treatment (Table 3). The mean decrease of MAP mesor in patients treated with Ca channel blockers, $\beta$-blockers and ACE inhibitors was $7 \mathrm{mmHg}, 14 \mathrm{mmHg}$ and $11 \mathrm{mmHg}$, respectively. Thus the hypotensive effect of $\mathrm{Ca}$ channel blockers was smaller than that of the remaining two agents. The group amplitude of MAP did not change after any of the drug treatments (Table 3). However, the changes in the individual amplitudes of MAP were different among the three drug groups. In each of the $\mathrm{Ca}$ channel blocker subgroups (Fig. 1a, b, c) and the $\beta$-blocker subgroup treated with

TABLE 3. Cosinor parameters of mean arterial

\begin{tabular}{llcccc}
\hline & & \multicolumn{4}{c}{ MAP } \\
\cline { 3 - 6 } & & $\begin{array}{c}\text { Mesor } \\
(\mathrm{mmHg})\end{array}$ & $\begin{array}{c}\text { Amplitude } \\
(\mathrm{mmHg})\end{array}$ & $\begin{array}{c}\text { \% Amplitude } \\
(\%)\end{array}$ & $\begin{array}{c}\text { Acrophase } \\
(\text { degree })\end{array}$ \\
\hline $\mathrm{Ca}^{\mathrm{b}}$ & Before & $103 \pm 15.3^{\mathrm{c}}$ & $8.6 \pm 5.3$ & $8.9 \pm 5.3$ & $179 \pm 46$ \\
& During & $96 \pm 13.2^{*}$ & $9.6 \pm 5.6$ & $10.1 \pm 5.5$ & $205 \pm 58$ \\
$\beta$ & Before & $100 \pm 9.0$ & $12.7 \pm 5.6$ & $12.3 \pm 5.3$ & $211 \pm 15$ \\
& During & $86 \pm 9.1^{* *}$ & $11.3 \pm 4.6$ & $13.3 \pm 5.7$ & $227 \pm 36$ \\
ACEI & Before & $101 \pm 11.5$ & $13.1 \pm 5.7$ & $13.5 \pm 6.4$ & $185 \pm 28$ \\
& During & $89 \pm 10.3^{*}$ & $12.3 \pm 4.9$ & $14.0 \pm 5.7$ & $208 \pm 26$ \\
\hline
\end{tabular}

${ }^{\mathrm{a}} \%$ Amplitude, Amplitude/Mesor $\times 100 .{ }^{\mathrm{b}} \mathrm{Ca}$, calcium channel blocker ; $\beta, \beta$ -

'Data are expressed as mean \pm S.D..

${ }^{*} p<0.05,{ }^{* *} p<0.01$ vs. values before treatment. 
atenolol (Fig. 2a), the amplitude of MAP increased in some patients but decreased in others during treatment. Such alteration of MAP amplitude was not so evident in individuals in the ACE inhibitor subgroup treated with enalapril (Fig. 3a). The acrophase of MAP was not affected by any of the drug treatments (Table 3). Ca channel blockers increased the amplitude of HR (Table 3). A typical example of a patient who demonstrated an increase in the amplitude of $\mathrm{HR}$ during treatment with $\mathrm{Ca}$ channel blockers is demonstrated in Fig 4 . The

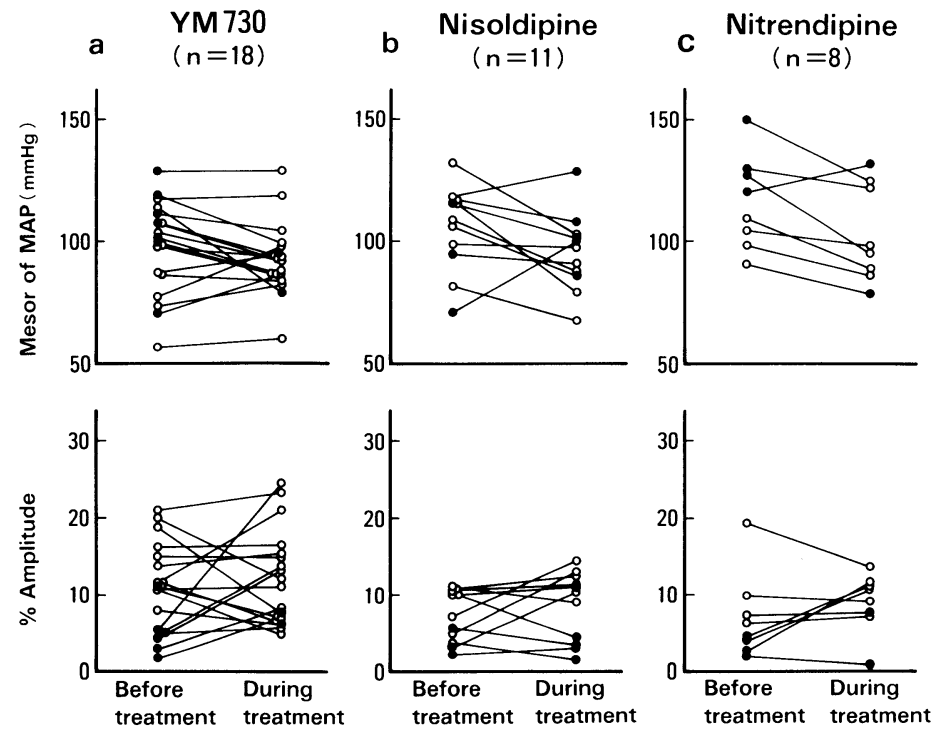

Fig. 1. The mesor and \%amplitude of mean arterial pressure before and during treatment with calcium channel blockers. $\bigcirc$, significant rhythm $(+)$; significant rhythm $(-)$.

pressure $(M A P)$ and heart rate $(H R)$ before and during treatment

\begin{tabular}{cccc}
\hline \multicolumn{3}{c}{ HR } \\
\hline $\begin{array}{c}\text { Mesor } \\
\text { (beats } / \text { min) }\end{array}$ & $\begin{array}{c}\text { Amplitude } \\
\text { (beats } / \text { min) }\end{array}$ & $\begin{array}{c}\% \text { Amplitude } \\
(\%)\end{array}$ & $\begin{array}{c}\text { Acrophase } \\
\text { (degree) }\end{array}$ \\
\hline $68 \pm 7.0$ & $6.9 \pm 2.6$ & $10.2 \pm 3.7$ & $201 \pm 36$ \\
$70 \pm 5.7$ & $9.2 \pm 3.3^{* *}$ & $13.0 \pm 4.9^{*}$ & $203 \pm 28$ \\
$66 \pm 6.1$ & $7.0 \pm 4.3$ & $10.4 \pm 5.8$ & $193 \pm 19$ \\
$58 \pm 5.3^{* *}$ & $4.4 \pm 2.0^{* *}$ & $7.6 \pm 3.4$ & $213 \pm 57$ \\
$68 \pm 8.3$ & $8.8 \pm 2.2$ & $12.9 \pm 2.6$ & $217 \pm 23$ \\
$69 \pm 9.2$ & $7.8 \pm 2.1$ & $12.1 \pm 3.4$ & $199 \pm 23$
\end{tabular}

blocker; ACEI, angiotensin-converting enzyme inhibitor. 


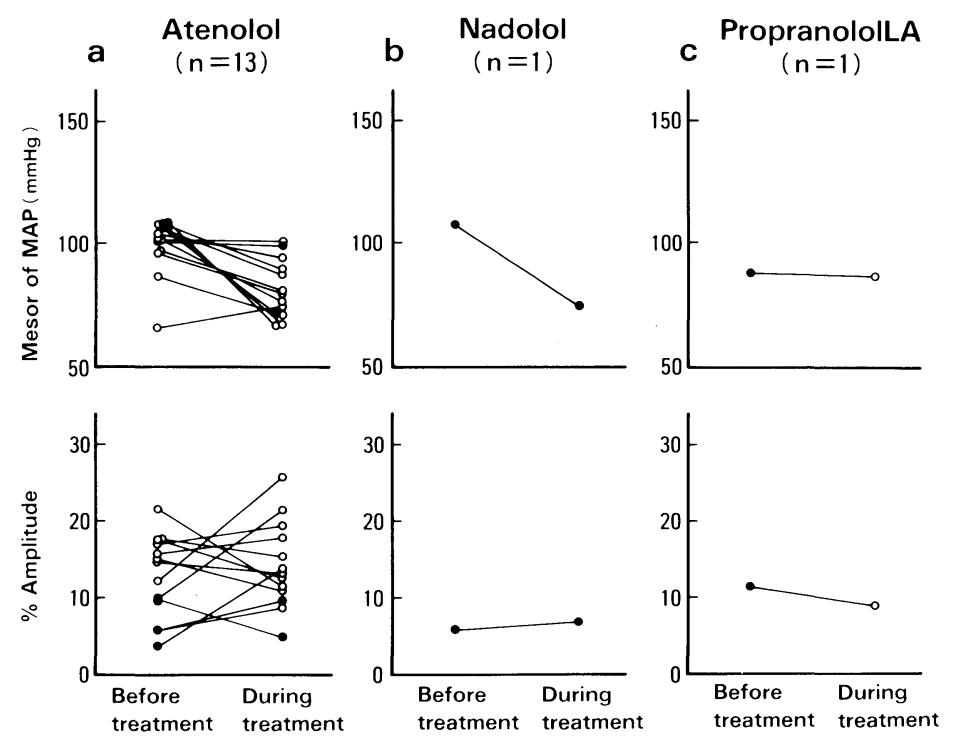

Fig. 2. The mesor and \%amplitude of mean arterial pressure before and during treatment with $\beta$-blockers. $\quad O$, significant rhythm $(+) ; \bullet$, significant rhythm $(-)$.

increase in amplitude was largely attributed to an acceleration of the morning rise in HR. In contrast, $\beta$-blockers suppressed the rapid increase of HR in the morning (Fig. 5) and reduced the amplitude and mesor of HR (Table 3). ACE inhibitors did not affect any circadian rhythm parameter of HR (Table 3).

\section{Discussion}

We examined the effects of antihypertensive drugs on circadian rhythms of BP and HR. The circadian rhythm was assessed by the cosinor method in an attempt to evaluate the drug effects on both population and individual basis. To avoid some artifact recordings in the use of non-invasive ABPM (Mancia et al. 1989), we used hourly mean values for cosinor analysis. This smoothing of the short-term variations of BP or HR may have improved both the validity of the data used for cosine fitting and the reproducibility of the constructed curve.

On a population basis, Ca channel blockers, $\beta$-blockers and ACE inhibitors decreased the mesor of MAP without changing the amplitude or acrophase. In other words, the three drug classes lowered BP throughout the day without changing circadian BP rhythm. On an individual basis, however, the changes in circadian $\mathrm{BP}$ rhythm in response to treatment were slightly different among the three drug classes. The amplitude of BP increased in some patients, while it decreased in others during treatment with Ca channel blockers or atenolol. Such contrary changes canceled one another, causing no change in the pooled data. The changes in the amplitude of $\mathrm{BP}$ in response to enalapril treatment were rather 

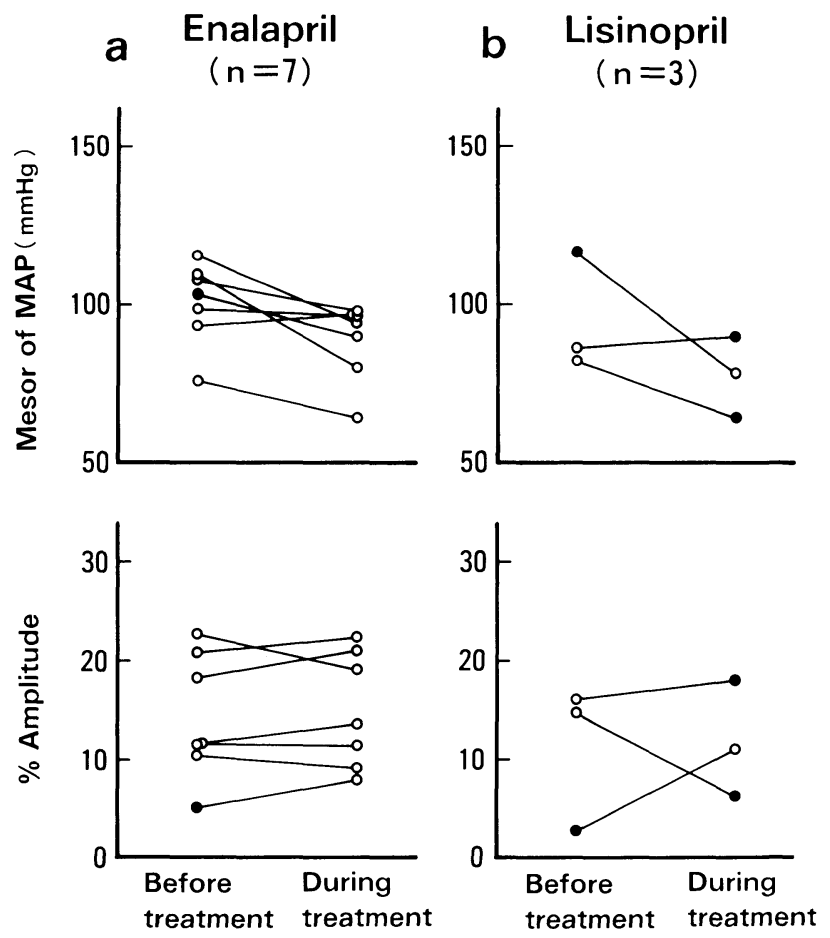

Fig. 3. The mesor and \%amplitude of mean arterial pressure before and during treatment with angiotensin-converting enzyme inhibitors. $O$, significant rhythm $(+)$; •, significant rhythm $(-)$.

uniform in all individuals. Since most previous studies assessed the effects of antihypertensive drugs on circadian $\mathrm{BP}$ rhythm using pooled data analysis, the response of circadian BP rhythm to drug treatment has never been clarified on an individual basis. This study indicates that the results obtained from population analysis do not accurately reflect the results from all individuals.

The changes in amplitude of BP were observed more frequently during treatment with $\mathrm{Ca}$ channel blockers or $\beta$-blockers than with ACE inhibitors. These different responses of circadian BP rhythm cannot be explained by the differences in the hypotensive effect since the reduction in BP was greater with $\beta$-blockers or ACE inhibitors than with $\mathrm{Ca}$ channel blockers. Although the mechanism mediating circadian BP rhythm is uncertain, the sympathetic tone may play a major role (Sowers 1981). Thus the different response of the BP amplitude in individuals treated with $\mathrm{Ca}$ channel blockers or $\beta$-blockers may partly be explained by the difference in the compensatory sympathetic response to the $\mathrm{BP}$ reduction by the treatment.

The reason we focused on the amplitude of $\mathrm{BP}$ is that this parameter can be an index of the nocturnal fall in BP. Recently much attention has been given to the subject of BP treatment during sleep (Tochikubo et al. 1991). It has been 

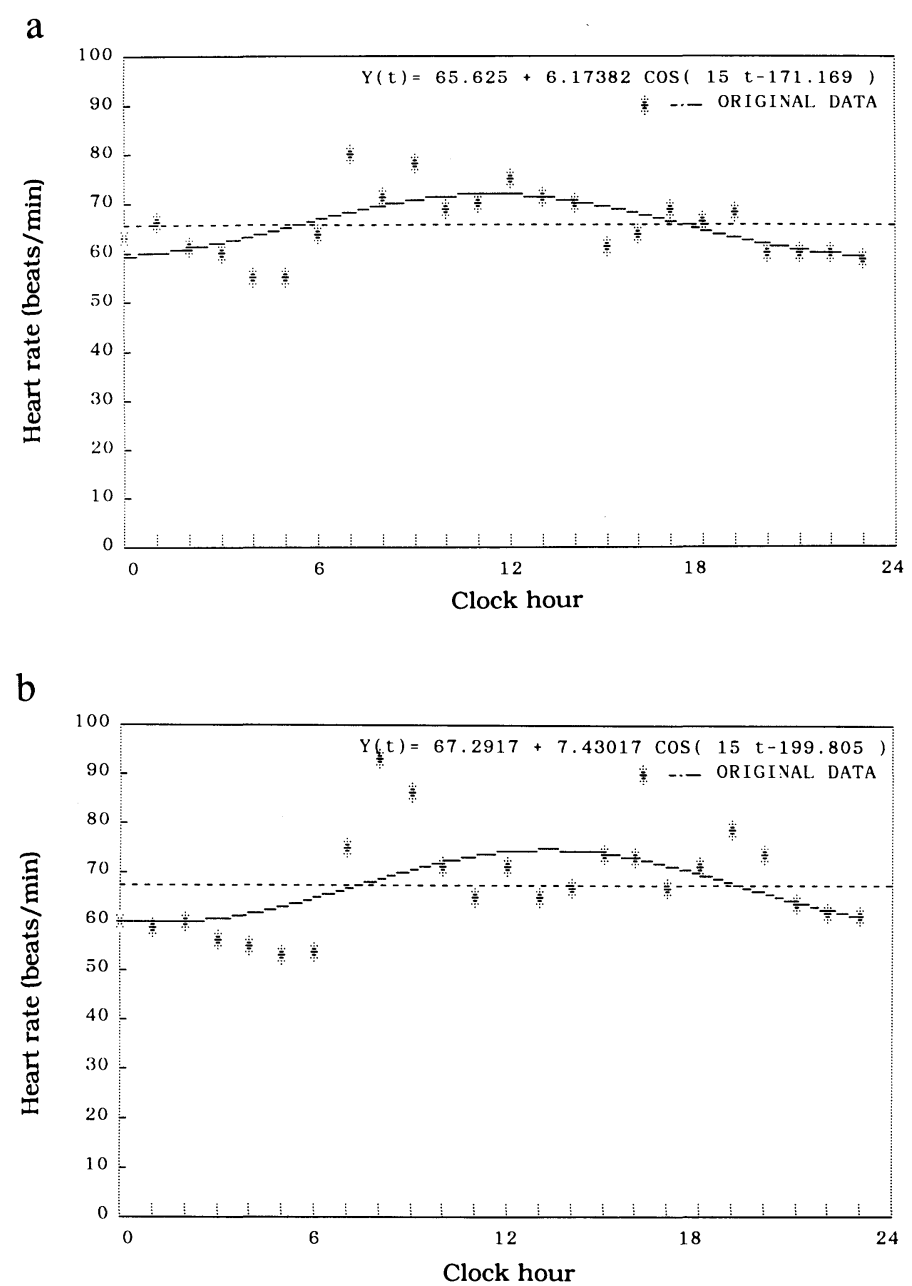

Fig. 4. A typical example of circadian heart rate rhythm before (a) and during (b) treatment with a calcium channel blocker.

suggested that BP behavior during sleep is linked to the development of cerebral infarction (Marshall 1977; Tsementzis et al. 1985). In this context, an accurate understanding of individual $\mathrm{BP}$ amplitude is essential for the adequate treatment of hypertension.

The present study demonstrated that $\mathrm{Ca}$ channel blockers, $\beta$-blockers and ACE inhibitors have different effects on the circadian HR rhythm. These results indicate that the three drug classes have different influences on the autonomic nervous systems which regulate circadian cardiac rhythm. $\beta$-Blockers suppressed morning increases in HR and reduced the amplitude and mesor of HR. MillarCraig et al. (1978b) reported that atenolol reduced HR throughout the day and flattened the circadian HR rhythm. Their results seem to be consistent with our 

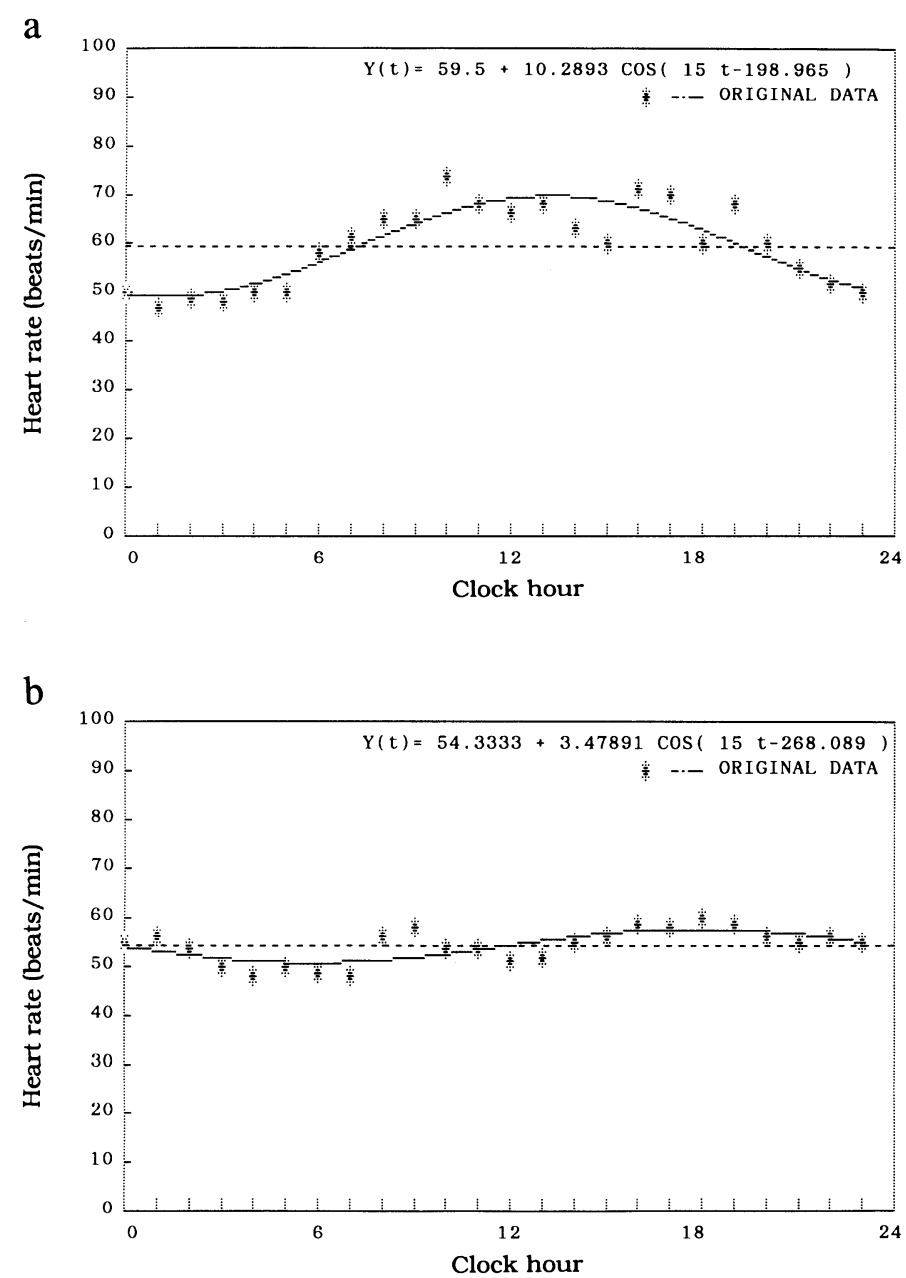

Fig. 5. A typical example of circadian heart rate rhythm before (a) and during (b) treatment with a $\beta$-blocker.

conclusions. On the other hand, Ca channel blockers increased the amplitude of $\mathrm{HR}$, an effect we attributed to an acceleration of the morning rise in HR. We did not clarify whether sympathetic activation or vagal inhibition mainly mediated the morning increase in HR during Ca channel blocker treatment. In any case, this phenomenon should be investigated since rapid increases in morning HR may precipitate cardiovascular events (Sirgo et al. 1988). Previous reports failed to confirm an enhancement of circadian HR amplitude by $\mathrm{Ca}$ channel blockers. This may be due to the difference in analytical methods. There are some phase differences between the circadian HR rhythm of individuals. Thus the construction of the circadian curve of averaged HR plotted over 24-hr period can lead to the canceling of opposite directional amplitudes. As a result, the amplitude of 
$\mathrm{HR}$ of each individuals can be underestimated. ACE inhibitors had no effect on circadian HR rhythm, indicating that this drug class has little influence on the autonomic control of the heart as compared to Ca channel blockers or $\beta$-blockers. The circadian rhythm of autonomic control of the heart could be an important underlying mechanism for the circadian distribution of cardiac events such as angina pectoris (Nademanee et al. 1987) and transient myocardial ischemia (Rocco et al. 1987). We speculate that $\mathrm{Ca}$ channel blockers, $\beta$-blockers and ACE inhibitors may affect the prognosis of ischemic heart disease in different ways. Further prospective studies are needed to verify this hypothesis.

\section{References}

1) Delea, C.S. (1979) Chronobiology of blood pressure. Nephron, 23, 91-97.

2) Floras, T.S., Jones, J.V., Johnston, J.A., Brooks, D.E., Hassan, M.O. \& Sleight, P. (1978) Arousal and the circadian rhythm of blood pressure. Clin. Sci. Mol. Med., 55, Suppl. 4, 395s-397s.

3) Halberg, F., Johnson, E.A., Nelson, E. \& Sothern, R. (1972) Autorhythmometry procedure for physiologic self-measurements and their analysis. Physiol. Teacher, 1, $1-11$.

4) Imai, Y., Abe, K., Sasaki, S., Minami, N., Munakata, M., Yumita, S., Onoda, Y., Sekino, H. \& Yoshinaga, K. (1987) A finger volume-oscillometric device for monitoring ambulatory blood pressure: Laboratory and clinical evaluation. Clin. Exp. Hypertens., A9, 2001-2025.

5) Mancia, G., Casadei, R. \& Mutti, G. (1989) Ambulatory blood pressure monitoring in the evaluation of antihypertensive treatment. Am. J. Med., 87, Suppl. 6B, 23-30.

6) Marshall, J. (1977) Diurnal variation in occurrence of strokes. Stroke, 8, 230-231.

7) Millar-Craig, M.W., Bishop, C.N. \& Raftery, E.B. (1978a) Circadian variation of blood pressure. Lancet, 1, 795-797.

8) Millar-Craig, M.W., Kenny, D., Mann, S., Balasbramanian, V. \& Raftery, E.B. (1978b) Effect of once-daily atenolol on ambulatory blood pressure. Br. Med. J., 1, 237-238.

9) Munakata, M., Imai, Y., Abe, K., Sasaki, S., Minami, N., Hashimoto, J., Sakuma, H., Ichijyo, T., Yoshizawa, M., Sekino, H. \& Yoshinaga, K. (1991) Assessment of age dependent changes in circadian blood pressure rhythm in patients with essential hypertension. J. Hypertens., 9, 407-415.

10) Nademanee, K., Intarachot, V., Josephson, M.A. \& Singh, B.N. (1987) Circadian variation in occurrence of transient overt and silent myocardial ischemia in chronic stable angina and comparison with prinzmetal angina in men. Am. J. Cardiol., 60, 494-498.

11) Nelson, W., Young, Y.L., Lee, J.K. \& Halberg, F. (1979) Methods for cosinorrhythmometry. Chronobiologia, 6, 305-323.

12) Rocco, M.B., Barry, J., Campbell, S., Nabel, E., Cook, E.F., Goldman, L. \& Selwyn, A.P. (1987) Circadian variation of transient myocardial ischemia in patients with coronary artery disease. Circulation, 75, 395-400.

13) Sirgo, M.A., Mills, R.J. \& DeQuattro, V. (1988) Effects of antihypertensive agents on circadian blood pressure and heart rate patterns. Arch. Intern. Med., 148, 2547-2552.

14) Sowers, J.R. (1981) Dopaminergic control of circadian norepinephrine levels in patients with essential hypertension. J. Clin. Endocrinol. Metab., 53, 1133-1137.

15) Tochikubo, O., Minamisawa, K., Miyakawa, T., Miyajima, E., Fujiki, Y. \& Ishii, M. (1991) Blood pressure during sleep : Antihypertensive medication. Am. J. Cardiol., 67, 18B-25B.

16) Tsementzis, S.A., Gill, J.S., Hitchcock, E.R., Gill, S.K. \& Beevers, D.G. (1985) 
Diurnal variation of and activity during the onset of stroke. Nerosurgery, 17, 901904.

17) Yamakoshi, K., Shimazu, H., Shibata, M. \& Kamiya, A. (1982a) New oscillometric method for indirect measurement of systolic and mean arterial pressure in the human finger. Part 1. Model experiment. Med. Biol. Eng. Comput., 20, 307-313.

18) Yamakoshi, K., Shimazu, H., Shibata, M. \& Kamiya, A. (1982b) New oscillometric method for indirect measurement of systolic and mean arterial pressure in the human finger. Part 2. Correlation study. Med. Biol. Eng. Comput., 20, 314-318. 